\title{
Antibody Seroprevalence and Rate of Asymptomatic Infections With SARS-CoV-2 in Austrian Hospital Personnel
}

Iris Leister

Paracelsus Medizinische Privatuniversitat https://orcid.org/0000-0002-5963-0598

\section{Elisabeth Ponocny-Seliger}

Sigmund Freud Private University Vienna: Sigmund Freud PrivatUniversitat Wien

Herwig Kollaritsch ( $\nabla$ dr.herwig.kollaritsch@gmail.com)

Institute of Specific Prophylaxis and Tropical Medicine, Medical University of Vienna, Vienna, Austria; https://orcid.org/0000-0001-6393-516X

\section{Peter Dungel}

Ludwig Boltzmann Gesellschaft

\section{Barbara Holzer}

Austrian Agency for Health and Food Safety

Johannes Grillari

Ludwig Boltzmann Gesellschaft

\section{Heinz Redl}

Ludwig Boltzmann Gesellschaft

Ivo Ponocny

MODUL University Vienna

\section{Claudia Wilfing}

Ludwig Boltzmann Gesellschaft

\section{Ludwig Aigner}

Paracelsus Medical University Salzburg: Paracelsus Medizinische Privatuniversitat

\section{Markus Exner}

Labors.at

Michaela Stainer

Ludwig Boltzmann Gesellschaft

\section{Matthias Hackl}

TAmiRNA GmbH

\section{Thomas Hausner}

AUVA: Allgemeine Unfallversicherungsanstalt

\section{Rainer Mittermayr}

AUVA: Allgemeine Unfallversicherungsanstalt

\section{Wolfgang Schaden}

AUVA: Allgemeine Unfallversicherungsanstalt 
Research article

Keywords: severe acute respiratory syndrome coronavirus 2, SARS-CoV-2, COVID-19 diagnostic testing

Posted Date: April 1st, 2021

DOl: https://doi.org/10.21203/rs.3.rs-366392/v1

License: (a) (1) This work is licensed under a Creative Commons Attribution 4.0 International License. Read Full License 


\section{Abstract}

Context: On March 11, the World Health Organization (WHO) announced the current corona virus disease 2019 (COVID-19) outbreak as a pandemic. The first laboratory-confirmed case of COVID-19 in Austria was announced on February 27, 2020. Since then, the incidence of infection followed an exponential increase until a complete lockdown in March 2020. Thereafter easing of restrictions was gradually introduced and until mid-August daily infections remained mostly below 5 per 100.000 population.

Objectives: The aims of this study are to determine i) how many employees in Austrian trauma hospitals and rehabilitation facilities have virus specific IgG and IgM, and/or neutralizing antibodies against SARS-CoV-2, ii) how many are active virus carriers (symptomatic and asymptomatic) during the study, iii) the antibody decline in seropositive subjects over a period of around six months, and iv) the utility of rapid antibody tests for outpatient screening.

Study Design: Open uncontrolled observational cross-sectional study.

Setting/Participants: A total of 3301 employees in 11 Austrian trauma hospitals and rehabilitation facilities of the Austrian Social Insurance for Occupational Risks (AUVA) participated in the study.

Study Interventions and Measures: Rapid antibody tests for SARS-CoV-2 specific IgG and IgM antibodies, and RTPCR tests based on oropharyngeal swab samples, as well as laboratory-based antibody tests using ELISA/PRNT were performed. The tests were conducted twice, with an interval of 42.4 \pm 7.7 (Min=30, Max=64) days. Additionally, participants filled out a questionnaire including questions related to personal health, traveling activities, living situation, as well as inquiries of symptoms and comorbidities. Antibody positive tested participants were re-tested with ELISA/PRNT tests at a third time point on average $188.0 \pm 12.8$ days after their initial test.

Results: In our study cohort, only 27 out of 3301 participants $(0.81 \%)$ had a positive antibody test at any time point during the study confirmed via neutralization test. Among participants who had positive test results in either of the antibody tests, $50.4 \%$ did not report any symptoms consistent with common manifestations of COVID-19 during the study period or within the preceding six weeks. In the group who tested positive during or prior to study inclusion the most common symptoms of an acute viral illness were rhinitis (21.9\%), and loss of taste and olfactory sense (21.9\%).

The rapid antibody test was generally more sensitive based on serum (sensitivity $=86.6 \%$ ) as compared to whole blood (sensitivity=65.4). Concerning both ELISA tests overall the Roche test detected 24 (sensitivity=88.9\%) and the Diasorin test 22 positive participants (sensitivity=81.5\%).

In participants with a positive PRNT, a significant decrease in PRNT concentration from $31.8 \pm 22.9(\mathrm{Md}=32.0)$ at $\mathrm{T} 1$ to $26.1 \pm 17.6(\mathrm{Md}=21.3)$ at $\mathrm{T} 2$ to $21.4 \pm 13.4(\mathrm{Md}=16.0)$ at $\mathrm{T} 3\left(\mathrm{c}^{2}=23.848, \mathrm{df}=2, \mathrm{p}<0.001\right)$ was observed $\left(c^{2}=23.848, d f=2, p<0.001\right)-$ with an average time of $42.4 \pm 7.7$ days between $\mathrm{T} 1$ and $\mathrm{T} 2$ and $146.9 \pm 13.8$ days between $\mathrm{T} 2$ and $\mathrm{T} 3$.

Conclusions: During the study period (May $11^{\text {th }}-$ December $21^{\text {th }}$ ) only $0.81 \%$ were tested positive for antibodies in our study cohort. The antibody concentration decreases significantly over time with $14.8 \%$ (4 out of 27 ) losing detectable antibodies. 


\section{Introduction}

The novel severe acute respiratory syndrome coronavirus 2 (SARS-CoV-2) was first reported in December 2019 in Wuhan, China. On March 11, the World Health Organization (WHO) announced the current "corona virus disease 2019" (COVID-19) outbreak as a pandemic. The first laboratory-confirmed case of COVID-19 in Austria was announced on February 27, 2020. The incidence of infection follows an exponential growth, and the mean basic reproduction number was estimated to range from 2.24 to $3.58 .{ }^{1}$ After a complete lockdown in March/April, the epidemiologic situation in Austria remained stable with daily infection numbers well below 5/100.000 population until mid of August. Recently the numbers of confirmed cases continue to increase daily indicating a second wave of infections. ${ }^{2}$

The incubation period, defined as the time from infection to symptom onset, falls within the range of 2-14 days with $95 \%$ confidence and has a mean of around 5 days. ${ }^{3}$ Backer et al. found similar results and reported an estimated mean incubation period of 6.4 days $(95 \% \mathrm{Cl}=5.6-7.7)$, ranging from 2.1 to 11.1 days (2.5th to 97.5 th percentile). ${ }^{4}$

It has been reported that some individuals, particularly persons of younger age, infected with SARS-CoV-2 remain asymptomatic while real-time reverse transcription polymerase chain reaction (RT-PCR) tests were positive., 5 Also, comparable levels of viral load in upper respiratory specimens were found in asymptomatic individuals and symptomatic patients. ${ }^{7}$ Asymptomatic or pre-symptomatic SARS-CoV-2 virus carriers represent a considerable pool for transmission of infection considering the communicable period is reported to be up to three weeks. ${ }^{8-11}$ However, the proportion of asymptomatic cases remains unclear, estimations from studies vary between $18 \%$ and $33.3 \% .{ }^{12}$ There is evidence that this group of persons may transmit the infection for a period of at least one week although remaining PCR-positive for several weeks. ${ }^{13}$ This is particularly important in health care settings where patients and employees are at risk for exposure and infection. ${ }^{14}$

RT-PCR of the viral nucleic acid can also yield to false-negative results. ${ }^{5,15-17}$ False negative rates of up to $20 \%$ have been reported leading to failure to quarantine infected individuals. ${ }^{18-20}$ Additional serological testing of virus specific IgG and IgM antibodies is recommended because antibodies represent longer lasting markers of infection with SARS-CoV-2 in contrast to methods of pathogen detection, with the latter being detectable only transiently at the time of pathogen presence at sites where diagnostic material is collected. ${ }^{5,21}$

Sensitivity rates as well as specificity rates of recently evolved and currently available rapid antibody tests are not yet reliable enough. ${ }^{16,26,27}$ Additionally, many of those tests are not entirely specific for the SARS-CoV-2 virus, because of a cross-reactivity to other human SARS viruses like HCoV-OC43, HCoV-HKU1, HCoV-229E and HCoVNL63. ${ }^{23}$ Therefore, it is recommended to evaluate the antibody status via laboratory based enzyme linked immunosorbent assay (ELISA) and / or plaque reduction neutralization test (PRNT). ${ }^{25}$

The aims of this study were to determine i) how many employees in Austrian trauma hospitals and rehabilitation facilities have virus specific IgG and IgM, and/or neutralizing antibodies against SARS-CoV-2, indicating that they have recovered from infection with or without having shown symptoms at any time, ii) how many were actively infected during the study period and did not show COVID-19 associated symptoms while included in the study, 
iii) the antibody decline in seropositive subjects over a period of around six months, and iv) the utility of rapid antibody tests for outpatient screening.

\section{Methods}

This is an open, uncontrolled, three-time cross-sectional study.

\section{Study population}

All employees in Austrian trauma hospitals and rehabilitation facilities of the Austrian Social Insurance for Occupational Risks (AUVA) have been invited to participate in the study. In total, 3301 hospital employees were enrolled in eleven participating hospitals and rehabilitation facilities in Austria. The mean(SD) age in the cohort was 43.8 (11.9) years, $2246(68 \%)$ are female, $1049(31.8 \%)$ are male, and $6(0.2 \%)$ refused to disclose their gender. Written informed consent has been obtained from all study participants.

\section{Study procedures}

The study procedures are depicted in figure 1. A rapid antibody test (chip based) for SARS-CoV-2 specific IgG and IgM antibodies, and an RT-PCR test based on oropharyngeal swab samples, as well as the ELISA / PRNT tests (if indicated) were offered to all employees in Austrian trauma hospitals and rehabilitation facilities. The rapid antibody tests and PCR tests were conducted twice, with 42.4 7.7 (Min=30, Max=64) days in between testing. The lab-based ELISA and/or PRNT was conducted only if the rapid antibody test showed a positive or questionable result or if a prior positive PCR was known. Participants who had positive antibody tests in ELISA and/or PRNT, were invited for a third blood sample collection 186.8 \pm 11.5 days after their initial positive result to determine antibody kinetics.

Individuals who agreed to participate in the study were asked to fill out an additional questionnaire to identify special risk factors which consisted of the following items:

- demographics (name, contact details, gender, age, height, bodyweight)

- code of the hospital or rehabilitation facility

- if the participant is a smoker including a quantification of smoking habit

- if the person had been tested for SARS-CoV-2 previously (with either an antibody test or a RT-PCR) including the test result

- survey flu like symptoms (at present or within the previous six weeks)

$\circ$ fever

- cough

○ dyspnea

- nasal congestion

- sore throat

- headaches 
- myalgia

- impaired sense of smell or taste

○ diarrhea

- questions related to the living situation

- how many people live in the same household

- how many adolescents below the age of 15 years live in the same household

○ inquiry of flu like symptoms within the family members / housemates

- questions related to commuting

- use of public transportation

- by car

- by bike

$\circ$ walking

- survey on traveling activities within the previous six weeks

- eastern Austria

- western Austria

- Italy

- within Europe

- outside of Europe

- attendance on large-scale events with more than 100 people within the last six weeks

- job description (divided into 25 categories: medical doctors, nurses, administrative staff, cleaning staff, medical-technical staff, laboratory staff, etc.)

- working hours within the last four weeks and periods of absence

- inquiry of comorbidities

$\circ$ hypertension

- diabetes mellitus

- coronary artery disease

- chronic obstructive pulmonary disease (COPD)

- chronic kidney disease

- inquiry of immunosuppression and allergies

- test results of the $\lg G$ and $\lg M$ antibody test

- test result of the RT-PCR test based on oropharyngeal swab samples

- test result of the ELISA / PRNT

The period of sample collection was from May 11th until August $23^{\text {rd }} 2020$ for the PCR and LFA, and until December $4^{\text {th }} 2020$ for the additional blood sample collection in subjects with positive results prior. 


\section{Real-time reverse transcription polymerase chain reaction (RT- PCR) tests}

\section{RNA Isolation}

Total RNA was isolated from $200 \mu \mathrm{L}$ of virus media using the commercially available Maxwell RSC Viral Total Nucleic Acid Purification Kit (Promega, AS1330) in combination with the Maxwell RSC48 system. Samples were mixed with $200 \mu \mathrm{L}$ lysis buffer, $20 \mu \mathrm{L}$ Proteinase $\mathrm{K}$, and $0.5 \mu \mathrm{L}$ internal positive control (IPC, Ingenetix Viroreal SARS \& SARS-CoV-2, DHUV02313x5) followed by vigorous mixing for a minimum of 10 seconds and 10 minutes incubation at room temperature. Afterwards samples were applied to Promega Maxwell cartridges and subject to automated processing on the Maxwell RSC 48 system according to the manufacturer's instructions. Samples were purified with paramagnetic particles that serve as mobile solid phase. Total RNA was eluted in $50 \mu \mathrm{l}$ nuclease-free water.

\section{SARS-CoV-2 Screening Assay}

The CE-IVD ViroReal SARS-CoV-2 \& SARS Kit (Ingenetix, Austria, Cat: DHUV02313x5) was used for detection of SARS-CoV-2 nucleocapsid RNA in the clinical sample material. Probes were designed to detect the nucleocapsid protein gene ( $\mathrm{N}$ gene) of SARS-CoV-2 as well as SARS-CoV and SARS-related coronavirus. Other beta coronaviruses are not detected with this kit. The primer and probe design chosen by this assay is not identical to the WHO design, as it intends to cover possible future changes in the virus sequence, therefore a highly conserved region in all SARS coronavirus clusters of the $\mathrm{N}$ gene was chosen as target region. This allows universal detection of all so far known SARS-CoV strains including SARS-CoV-2 and SARS-like CoV without discriminating between strains.

The test uses a one-step reverse transcription real-time PCR (RT-PCR) reaction. A probe-specific amplification curve at $530 \mathrm{~nm}$ (FAM channel) indicates the amplification of virus-specific RNA. An internal RNA positive control (RNA IPC) is detected in Cy5 channel and was used as internal PCR control for both RNA extraction as well as RTPCR efficiency. The target for the RNA IPC is extracted together with the sample. To set up the reaction $5 \mu \mathrm{L}$ isolated RNA were mixed with $2 \mu \mathrm{L}$ nuclease free water (NFW), $2.5 \mu \mathrm{L}$ reaction mix and $0.5 \mu \mathrm{L}$ SARS-CoV-2 \& SARS Assay Mix + RNA IPC Assay Mix. RT-qPCR was performed under following conditions: RT: $50^{\circ} \mathrm{C}$ for $15 \mathrm{~min}$, Activation: $95^{\circ} \mathrm{C}$ for $20 \mathrm{sec}$, PCR 45 cycles: $95^{\circ} \mathrm{C}$ for $5 \mathrm{sec}$ and $60^{\circ} \mathrm{C}$ for $30 \mathrm{sec}$. Cycle of quantification (Cq) was calculated with the second derivative maximum method.

\section{SARS-CoV-2 Confirmation Assay}

Positive results from the screening assay SARS-CoV-2 were confirmed on the basis of an independent detection of the SARS-CoV-2 specific E-Gene. This protocol is based on a publication from Corman et al. "Detection of 2019 novel coronavirus (2019nCoV) by real time-RT-PCR" ${ }^{28}$ using Superscript III RT-qPCR System (Thermo Fisher, Cat: 12574026). Per reaction, 3.44 $\mu \mathrm{L}$ RNA were mixed with $5 \mu \mathrm{L}$ reaction mix, $0.4 \mu \mathrm{L}$ RT/Polymerase, $0.4 \mu \mathrm{L}$ $1 \mu \mathrm{g} / \mu \mathrm{L}$ BSA, $0.16 \mu \mathrm{L} \mathrm{MgSO} 4$ and $0.2 \mu \mathrm{L}$ of each E-Gene forward and reverse primer and probe. RT-qPCR is performed under following conditions: RT: $55^{\circ} \mathrm{C}$ for $10 \mathrm{~min}$, Activation: $95^{\circ} \mathrm{C}$ for $3 \mathrm{~min}$, PCR 45 cycles: $95^{\circ} \mathrm{C}$ for 15 
sec and $58^{\circ} \mathrm{C}$ for $30 \mathrm{sec}$. Cq-value was calculated with the second derivative maximum method. Sequences of the used primers and probes are shown below.

\begin{tabular}{|lll|}
\hline Gene \& Reagent & Sequence & Conc. ${ }^{*}$ \\
\hline E-Gene FW Primer & ACAGGTACGTTAATAGTTAATAGCGT & $400 \mathrm{nM}$ \\
\hline E-Gene Rev Primer & ATATTGCAGCAGTACGCACACA & $400 \mathrm{nM}$ \\
\hline E-Gene Probe & /5Cy5/ACACTAGCCATCCTTACTGCGCTTCG/3BHQ_2/ & 200nM \\
\hline
\end{tabular}

* concentration in $\mathrm{nM} / \mathrm{L}$ based on the final reaction mix, e.g. $1.5 \mu \mathrm{L}$ of a $10 \mu \mathrm{M}$ primer working solution per $25 \mu \mathrm{L}$ total reaction yields a final concentration of $600 \mathrm{nM}$ as indicated in the table.

\section{Rapid antibody test: SARS-CoV-2 Antibody lateral flow assay (LFA)}

LFAs were performed according to the instructions-for-use (TAmiRNA GmbH, Austria). In brief, all test components were brought to room temperature. Sera or plasma aliquots were completely thawed before testing, or whole blood was freshly collected using safety lancets. The test cassette was removed from the sealed pouch and the required amount of sample ( $20 \mu \mathrm{l}$ serum/plasma or $20 \mu \mathrm{l}$ whole blood) was pipetted into the specimen well using clean disposable pipets. Immediately after the sample was applied to the sample inlet, three drops of sample buffer were applied to the buffer well. Results were read within the specified time window of 15 minutes.

\section{Laboratory-based ELISA (Roche and Diasorin)}

SARS-CoV-2 specific antibodies were measured from serum samples with two assays: (i) a qualitative eCLIA assay targeting pan-immunoglobulin (IgM, IgA, IgG) antibodies against the nucleoprotein ( $\mathrm{N}-\mathrm{Ag}$ ) (Roche Elecsys Anti-SARS-CoV-2) on a cobas e601 analyzer. Samples with a cutoff index $\mathrm{COI}<1.0$ are classified as non-reactive. (ii) a quantitative CLIA assay targeting IgG antibodies against the S1/S2 protein (Diasorin LIAISON SARS-CoV-2 $\mathrm{S} 1 / \mathrm{S} 2 \mathrm{lgG}$ ) on a LIAISON XL analyzer. Results are expressed in arbitrary units (AU/ml). Samples with $<12,0$ $\mathrm{AU} / \mathrm{ml}$ are classified as negative; $12,0 \leq \mathrm{x}<15,0$ as borderline and $\geq 15,0$ as positive.

According to the manufacturer, for the Roche Elecsys Anti-SARS-CoV-2 assay sensitivity rates range between $65.5 \%$ and $100 \%$ depending on the time between diagnosis and sample collection (65.5\% 0-6 days, $88.1 \%$ 7-13 days, and $100 \%$ more than 14 days after diagnosis, respectively).

Sensitivity rates for the Diasorin LIAISON SARS-CoV-2 S1/S2 IgG range between $25 \%$ and $97.4 \%$ and are also dependent on the time since diagnosis via RT-PCR according to the manufacturer ( $25 \%$ less than 5 days, $90.4 \%$ 5-15 days, and $97.4 \%$ more than 15 days after diagnosis).

\section{Neutralization test}

\section{Cell lines and viruses}


Vero 76 clone E6 cells (CCLV-RIE929, Friedrich-Loeffler-Institute, Riems, Germany) were cultured in minimum essential medium Eagle (E-MEM) with Hank's balanced salt solution (HBSS) (BioWhittaker, Lonza, Szabo Scandic, Austria), supplemented with 10\% fetal bovine serum (Corning, Szabo Scandic, Austria) (FBS) and were used to titrate virus preparations and for the neutralization assays. Vero E6 TMPRSS-2 (provided by Stefan Pöhlmann; Deutsches Primatenzentrum, Göttingen, Germany) - initially described in Hoffmann et al. - were cultured in Dulbecco's modified Eagle's medium (DMEM) with 10\% fetal bovine serum (FBS) and used for virus passaging and isolating infectious virus from clinical samples. ${ }^{29}$ The virus used for the neutralization assay was originally isolated from a clinical specimen (NP swab), taken in mid-March 2020, and further passaged twice on Vero E6 TMPRSS-2 cells.

\section{Neutralization assay}

The neutralization assay was set up in flat-bottom 96-well tissue culture plates. Human sera were heat-treated for $30 \mathrm{~min}$ at $56^{\circ} \mathrm{C}$ and diluted 1 to 4 in triplicates in serum-free DMEM medium as starting point for the assay. Twofold serially diluted sera were incubated with an equal volume of $50 \mu \mathrm{SARS}-\mathrm{CoV}-2$ at a minimum of 2,000 tissue culture infectious dose $50 \%$ (TCID50)/ml) for 90 min at $37^{\circ} \mathrm{C}$. Next, 25,000 Vero 76 clone E6 cells were added to the serum/virus mixture in each well in a volume of $100 \mu \mathrm{l}$ in EMEM, supplemented with $10 \%$ FBS and incubated for 4 days at $37^{\circ} \mathrm{C}, 5 \% \mathrm{CO} 2$ in a humidified incubator. The CPE in every well was scored under an inverted optical microscope and the reciprocal of the highest serum dilution that protected more than $50 \%$ of cells from CPE was taken as the neutralizing titer.

PRNT was used as a reference in this study because neutralization assays are proposed to have the highest validity for CoV serology. 23

\section{Statistical analysis}

Statistical analysis was performed using SPSS statistical software (version 26, SPSS Inc., Chicago, Illinois, USA). Figures were compiled with Biorender.com, draw.io, and Microsoft Excel (Microsoft Corp., Redmond, WA, USA). Results of the PCR and rapid antibody test (IgG and $\operatorname{lgM}$ ) were included in the eCRF at both time points together with all questionnaire data. If an ELISA and / or PRNT was indicated, results of these tests have also been included in the eCRF.

The sensitivity of the rapid antibody and ELISA test was calculated with respect to the neutralization test for all three time points separately. As blood was only sampled in case of a positive prior PCR or a positive or questionable rapid antigen test, sensitivity estimations are biased in favor of these tests and specificity cannot be determined.

Data are analyzed exploratively; for comparison of groups concerning sociodemographic and medical variables chi-square-tests and t-tests depending on the scale are applied. Reduction in antibody concentration between time points is tested via Friedman test and Spearman correlation is used to evaluate dependencies between reduction in antibody concentration, age of the participants, and days between T1/T2 and T2/T3, respectively.

\section{Results}


Details on demography and occupation of the study participants are summarized in table 1.

At first time point (T1), a total of $n_{1}=3301$ hospital employees could be enrolled whereby sociodemographic variables (see table 1) were comparable to the total AUVA population. At the second test time point (T2), which was on average $40.1 \pm 9.8$ days later, a reduced number of $n_{2}=2941$ could be re-tested by means of a PCR test.

Within the study cohort, 334 persons $(10.1 \%)$ had comorbidities that are considered to be associated with a more severe course of disease in Covid-19 (see table 2). Among the participants with comorbidities, 257 (7.8\%) had hypertension, 41 (1.2\%) had diabetes mellitus, 19 (0.6\%) had coronary artery disease, 43 (1.3) had COPD, and 14 (0.4\%) had chronic kidney disease. These 334 individuals, together with an additional 31 (0.9\%) immunocompromised persons are considered a risk group in the event of infection with SARS-CoV-2. Furthermore 1116 (33.8\%) participants reported to have allergies. (table 2)

A total of 769 (23.3\%) employees are smokers, whereby 513 (15.5\%) smoke between six and 15 cigarettes per day, $212(6.4 \%)$ smoke more than 15 cigarettes per day, and 44 (1.3\%) stated to use other products containing nicotine. Chi-squared analysis revealed that in individuals who smoke, the incidence of flu-like symptoms within six weeks before study enrollment was significantly higher (11\%) compared to non-smokers $(9 \%, p<0.001$, Cramer $\mathrm{V}=0.71)$.

\section{Active virus carriers during the study period}

Only one person had a positive PCR test result at T1 on May $12^{\text {th }}$. This participant was a medical doctor, who already tested positive 60 days before study inclusion and is therefore allocated to group $A$ in our analysis.

\section{Participants with positive test results}

A total of $n_{P}=32$ participants were tested SARS-CoV-2 positive at any time point either prior to the study (i.e. prior positive PCR-Test = Group A) or were tested positively for antibodies during the study (positive or questionable/inconclusive rapid antibody test and/or positive ELISA (Roche and/or Diasorin) = Group B). (Sociodemographic and health characteristics of these groups can be found in table 1 and table 2, respectively.) Nineteen (59.4\%) out of 32 test-positive participants reported no symptoms of an acute viral illness within six weeks prior to study enrollment as well as during the study period.

PRNT was performed if any antibody test was positive. Due to limited serum sample availability in 4 out of 32 participants, PRNT was performed on 28 sera with 25 out of which neutralizing activity was observed (one test was questionable). One participant lost neutralizing antibodies between T1 and T2 and another three participants lost them between T2 and T3.

Concerning clinical signs, rhinitis (21.9\%) and loss of taste and olfactory sense were the most prominent symptoms (21.9\%; table 3 ) in the group who tested positive at any time during or prior to study inclusion. 


\section{Group A: Participants with a positive PCR test prior to study inclusion}

Fifteen employees had positive PCR test results for acute SARS-CoV-2 infection prior to study inclusion, with an average of $44.5 \pm 20.0$ days between a prior positive PCR and T1 in the present study. Out of these, eight persons suffered from symptoms in the preceding six weeks.

Thirteen of these employees showed a positive neutralization test, for one participant the neutralization test result was below the threshold of a 1:4 dilution, and for another participant no blood sample could be obtained. Based on the blood samples only for seven of these participants the rapid antibody test was positive - including the person with the neutralization value below the threshold - so the sensitivity for the rapid antibody test in group A at T1 was only $46.2 \%$ (figure 3 ). Using the rapid antibody test with serum nine positive results (sensitivity $=69.2 \%$ ) and the one participant with the neutralization value below the threshold could be detected correctly.

A total of thirteen participants had a positive ELISA- test from Roche again including the one person with the neutralization test below the threshold, resulting in a sensitivity of $92.3 \%$ when compared with the neutralization test. Based on the ELISA- test from Diasorin ten participants were positive, again including the NT negative participant (sensitivity=69.2\%).

At the second timepoint (T2), a neutralization test result could only be obtained for eleven participants (all of them have tested positive at T1). The rapid antibody test based on whole blood was only positive for four of them (sensitivity $=36.0 \%$ ), while based on blood serum it was positive for seven (sensitivity=64\%). Concerning both ELISA tests the Roche test detected all eleven positive participants (sensitivity=100\%) and the Diasorin test only nine positive participants (sensitivity=82\%).

For twelve participants a neutralization test result was obtained at (T3), showing that two persons lost their antibodies between T2 and T3 (marked with T3(-) in figure 3); both ELISA tests detected all nine positive participants (sensitivity=100\%), the Roche test resulted in one false positive whereas the Diasorin test detected all three negative participants correctly.

Concerning those participants where a positive neutralization test was obtained, a significant decrease of the value from 26.5 $\pm 14.7(\mathrm{Md}=32.0)$ at T1 to $21.8 \pm 16.2(\mathrm{Md}=16.0)$ at T2 and to 17.8 $\pm 9.8(\mathrm{Md}=16.0)$ at T3 could be seen $(\mathrm{c} 2=10.4, \mathrm{df}=2, \mathrm{p}=0.006)$ - with an average time between T1 and T2 of $40.3 \pm 6.1$ days and between T2 and T3 of $151.6 \pm 8.1$ days.

\section{Group B: Participants with a positive antibody test during the study, either rapid antibody and/or ELISA at T1 and/or T2}

Seventeen employees were tested positive for antibodies during the study, either with the rapid antibody test and/or one of the ELISA tests, whereby the latter were only performed in individuals with a prior positive or questionable rapid antibody test. For 14 of these participants a neutralization test for validation could be performed. The majority was asymptomatic as only five participants reported symptoms in the preceding six weeks. 
At T1, 14 persons of group B had a positive rapid antibody test based on whole blood, which could be confirmed for ten persons via neutralization test (sensitivity $=83.3 \%$; figure 4). Using blood serum for the rapid antibody test, which was available only for 13 persons, all of them were positive - compared with the neutralization test but also one negative participant and one participant with a questionable result (sensitivity=100\%).

The ELISA-Roche test was positive for nine persons (sensitivity=81.8\%) and the ELISA-Diasorin test was positive for ten persons (sensitivity=90.9\%) again compared to the neutralization test (figure 4). At T2 neutralization tests could be performed for fifteen persons; one additional person who had a negative PCR and negative rapid antibody test at T1 but reported on flu-like symptoms prior to T1 was tested positive at T2 (No 16, marked T2(+) in figure 4) and one person seemingly lost his/her antibodies in the 41 days after T1 (No 21 ,marked T2(-) in figure 4). Based on whole blood, 12 persons were tested positive with the rapid antibody test, whereby ten cases (sensitivity=83.0\%) which also showed neutralization activity. Although, based on blood serum, 14 persons had positive results in the LFA, 11 of which also showed neutralization activity (sensitivity=92.0\%). The ELISA-Roche showed a sensitivity of $92 \%$ and the ELISA-Diasorin one of $100 \%$ for T2 using PRNT as reference.

Thirteen participants could be re-tested at T3 with the neutralization test showing a positive result for eleven persons. One additional participant became positive (No 17, marked with T3(+) in figure 4) which had so far only been positive in the rapid antibody test at T1 and T2, but reported flu-like symptoms between T2 and T3. Another person lost detectable antibodies (No 23, marked with T3(-) in figure 4). The ELISA-Diasorin test correctly identified all positive (sensitivity $=100 \%$ ) and negative participants while the ELISA-Roche test resulted in one false negative result (sensitivity=91\%).

Concerning those four participants (no 17, 18, 19,20) who are marked with an asterisk in figure 4 , only the rapid antibody test was positive either at T1 and/or T2 - so it may be hypothesized that they have always been false positive in the rapid antibody test and participant no 17, who showed antibodies at T3 most probably had corona between T2 and T3.

Also, in group B a significant decrease in the neutralization test value from $37.5 \pm 29.0(\mathrm{Md}=32.0)$ at $\mathrm{T} 1$ to 30.1 $\pm 18.6(\mathrm{Md}=26.7)$ at T2 to 24.4 $\pm 15.6(\mathrm{Md}=28)$ at T3 could be seen $\left(\mathrm{c}^{2}=14.389, \mathrm{df}=2, \mathrm{p}=0.001\right)-$ with an average time of $43.7 \pm 8.5$ days, and $143.6 \pm 16.2$ days between T1 / T2, and T2 / T3, respectively.

The rapid antibody test shows a low sensitivity of only $43.2 \%$ (T1)/36\% (T2) based on blood and 69.2\% (T1)/64\% (T2) based on serum in a group of participants who had been PCR positive recently. But, if a positive or questionable rapid antibody test result was obtained, the result could be confirmed via PRNT at the same time of sample collection for $83.3 \%$ (T1)/83\% (T2) based on blood and 100\% (T1)/92\% (T2) based on serum.

Summarizing these findings, the ELISA-Roche shows higher sensitivity than ELISA-Diasorin in participants who have been positive a priori, but in validating the rapid antibody test results ELISA-Diasorin outperformed ELISARoche.

\section{Decline of antibody concentration}

PRNT values showed a significant decrease from 31.8 $\pm 22.9(\mathrm{Md}=32.0)$ at T1 to $26.1 \pm 17.6(\mathrm{Md}=21.3)$ at T2 to $21.4 \pm 13.4(\mathrm{Md}=16.0)$ at T3 $\left(c^{2}=23.848, d f=2, p<0.001\right)-$ with an average time of $42.4 \pm 7.7$ days between $\mathrm{T} 1$ and T2 and 146.9 \pm 13.8 days between T2 and T3. Only two participants maintained their antibody titers at all three 
time points. Generally, the decrease in concentration is independent of the time period between T1/T2 and $\mathrm{T} 2 / \mathrm{T} 3$, respectively $\left(\mathrm{r}_{\mathrm{T} 1 / \mathrm{T} 2}=.065, \mathrm{p}_{\mathrm{T} 1 / \mathrm{T} 2}=0.775 ; \mathrm{r}_{\mathrm{T} 2 / \mathrm{T} 3}=.042, \mathrm{p}_{\mathrm{T} 1 / \mathrm{T} 2}=0.861\right)$.

\section{General antibody seroprevalence}

No difference in terms of antibody seroprevalence was observed between male and female participants, smokers and non-smokers, the geographical area of the participating center, or the presence of comorbidities or allergies $(p>0.05)$. Only medical doctors were slightly overrepresented $(p=0.097)$ in the group of positive cases, and individuals who were tested positive showed somewhat more traveling activities, especially outside Europe in February/March $(p=0.010)$. The number of persons per household was even slightly smaller $(2.34 \pm 1.5$ vs. $2.73 \pm 1.32 ; z=1.783, p=.075)$ in the group of persons with antibody seroprevalence with no differences according to the number of children below the age of 15 years $(p>0.05)$. Only seven persons reported of cohabitants with flu-like symptoms at least six weeks prior to the study whereby five had symptoms themselves (the neutralization test confirmed antibody seroprevalence for six persons and for one person the results were questionable). Also, asymptomatic persons do not differ from symptomatic ones in the neutralization test values ( $p>.0 .05)$. Finally, persons with positive seroprevalence do not differ according to how they reach their work place (public transport, car, bicycle or walk; $p>0.05$ ).

\section{Discussion}

In our study cohort, only 32 out of 3301 participants $(0.96 \%)$ had a positive antibody test at any time point during the study whereby results could be confirmed for 27 via neutralization test. This is remarkably lower compared to a large multicenter study in the USA, where $6 \%$ had detectable SARS-CoV-2 antibodies. ${ }^{14}$ Also, a large study on 61075 residents of Spain reported a seroprevalence between 4.6 and 5\% (by point-of-care test and immunoassay, respectively) where sample collection took place between April 27 and May 11, 2020. ${ }^{30}$ Another study by Korth et al. on 316 healthcare workers who had contact to COVID-19 patients in a tertiary hospital in Essen, Germany found a SARS-CoV-2-IgG antibody seroprevalence of 1.6\% between March 25th and April 21th, 2020. ${ }^{31}$ This may be partly explained by the different epidemiological situation in the respective countries. Austria had a low incidence during sample collection of this study with a 14-day notification rate of reported cases per 100000 population ranging between 0.0 and 88.2 during the study period (May $11^{\text {th }}-$ August $23^{\text {rd }}$ ). ${ }^{32}$ Additionally, the occupational risk was reduced in the participating trauma hospitals/rehabilitation centers because infected patients have been transferred to specifically implemented corona wards in other hospitals in Austria.

\section{Asymptomatic cases}

Among participants who had positive test results in either of the antibody tests, $50.4 \%$ did not report any symptoms consistent with common manifestations of COVID-19 (fever, fatigue, dry cough, dyspnea, nasal congestion, headaches, myalgia, or diarrhea ${ }^{1,9,33-35}$ ) in the preceding weeks irrespective of their age. Previous literature reported that around $30 \%$ of seropositive participants were asymptomatic. ${ }^{21,30,36}$ Antibody levels were lower in smokers and in women who had a less severe course of disease of COVID-19, and were generally elevated in older adults. ${ }^{21}$ 


\section{Sensitivity and specificity of antibody tests}

Sensitivity and specificity rates of different SARS-CoV-2 antibody tests vary between $53 \%$ and $94 \%$, and between $91 \%$ and $99.5 \%$, respectively. ${ }^{37}$ Due to the pandemic, an urgent need for outpatient and rapid field detection of antibodies against SARS-CoV-2 virus emerged. Therefore, a valid antibody test it is of utmost interest for society and previous literature has reported about validity of several rapid antibody tests:

Li et al. used the SARS-CoV-2 rapid IgG-IgM combined antibody test kit to detect IgM and lgG antibodies against SARS-CoV-2 virus in human blood. The study reported a sensitivity of $88.66 \%$, and a specificity of $90.63 \%$, considering a positive test result if $\operatorname{lgM}$, or $\operatorname{lgG}$, or both are positive. In their study, $64.48 \%$ (256 out of 397) of positive patients had both IgM and IgG antibodies 8-33 days after infection symptoms appeared, and test results from venous blood and fingertip blood matched with $100 \%$ consistency. ${ }^{26}$ Another study by Lee and colleagues used the ALLTEST 2019-nCoV IgG/ IgM Rapid Test Cassette and found a sensitivity of 100\%, a specificity of $98.0 \%$, and an accuracy rate of $98.6 \%$ for the anti-SARS-CoV-2 IgG antibody. IgG appeared at post-exposure 18-21 days or the illness day 11 . The relative sensitivity for the $\operatorname{lgM}$ antibody was reported to be $85 \%(95 \% \mathrm{Cl}, 62.1 \%$ $96.8 \%)^{27}$

In contrast, sensitivity rates of the antibody lateral flow assay in our study showed a wide variation ranging between 36.0\% and 69.2\% depending on the type of sampling (whole blood or serum) and the time point of sample collection (T1 vs. T2) in the group who had tested positive via PCR prior to study inclusion. Surprisingly, sensitivity rates were higher in participants with a positive antibody test during the study and no positive PCR prior to the study, ranging between $83.0 \%$ and $100 \%$. The rapid antibody test generally shows higher sensitivity when based on serum than on whole blood.

Summarizing these results, the rapid antibody test based on whole blood can - at best - be used for a prescreening for suspected cases. Based on serum, the test showed better sensitivity which may be due to higher antibody concentration in serum versus whole blood..

In our study, the ELISA tests showed an overall sensitivity of $88.9 \%$ in the Roche test and $81.5 \%$ in the Diasorin test using the neutralization test as a reference.

\section{Antibody production and waning}

Guo et al. conducted a longitudinal study on 82 confirmed and 58 probable cases using a nucleocapsid-based ELISA and found that the production of $\lg M, \lg A$ and $\lg G$ antibodies against SARS-CoV-2 were positive as early as day one after symptom onset. The median duration of IgM and IgA antibody detection were 5 days (IQR 3-6), while IgG was detected 14 days (IQR 10-18) after symptom onset. IgM antibody levels increased between days 8-14; but did not increase further between days 15-21, or after day 21 . The IgG antibodies could be detected on days $0-7$, and continued to increase on days $8-14$, as well as days $15-21$, and plateaued by day $21 .{ }^{16}$

Previous literature reported, that antibodies remained stable for four months after diagnosis ${ }^{21,36}$ In our study, a significant decline in neutralizing antibody concentration was observed between time points of testing within a period of approximately six months, but PRNT tests remained well above threshold in most patients indicating persistence of neutralizing antibodies. This result supports national vaccination recommendations in post-COVID 
patients which recommend suspending vaccination in such individuals. ${ }^{38,39}$ This is in contrast to US recommendations (no suspension of vaccination). ${ }^{40}$

\section{Limitations}

Antibody seroprevalence may be underestimated if participants had not yet produced a sufficient antibody response at the time of sample collection, or if antibody titers had already declined since the infection. We tried to reduce this bias by conducting the PCR and LFA tests twice with approximately six weeks in between testing (between T1 and T2) and an additional serum sample collection for ELISA / PRNT after another three months (between T2 and T3).

\section{Conclusion}

This study identified the following factors related to SARS-CoV-2 infection among health care workers in Austrian trauma centers and rehabilitation facilities: During the study period (May $11^{\text {th }}-$ December $21^{\text {th }}$ ) only $0.81 \%$ were tested positive for neutralizing antibodies, indicating that non-pharmaceutical interventions and other epidemiological interventions as recommended in Austria at the time of the study were widely effective in keeping infection rates low.

The antibody concentration in individuals who tested positive for a SARS-CoV-2 infection decreases significantly over a period of six months with $14.8 \%$ (4 out of 27 ) losing detectable antibodies.

Also, the results of rapid antibody tests are questionable due to a wide variability in their sensitivity rates.

\section{Declarations}

\section{Funding}

The project was funded by the Austrian Social Insurance for Occupational Risks (AUVA) and the authors would like to express their sincere appreciation.

\section{Conflicts of interest}

None to declare.

\section{Availability of data and material}

Data can be made available upon reasonable request to the corresponding author.

\section{Code availability}

Code can be made available upon reasonable request to the corresponding author.

\section{Ethics approval}

All procedures performed in this study were in accordance with the ethical standards of the institutional and national research committee and with the 1964 Helsinki declaration and its later amendments or comparable ethical standards. The study was approved by the ethics committee of the Austrian social insurance for 
occupational risks (AUVA) (Vote No. 04/2020). The study was registered on the ClinicalTrials.gov database (unique identifier: NCT04354779).

\section{Consent to participate}

All participants provided written, informed consent.

\section{Consent for publication}

All authors have read and approved the manuscript.

\section{References}

1. Lai C-C, Shih T-P, Ko W-C, Tang H-J, Hsueh P-R. Severe acute respiratory syndrome coronavirus 2 (SARS-CoV2) and coronavirus disease-2019 (COVID-19): The epidemic and the challenges. Int J Antimicrob Agents. 2020;55(3):105924. doi:10.1016/j.jjantimicag.2020.105924

2. Amtliches Dashboard COVID19: öffentlich zugängliche Informationen. Bundesministerium für Soziales, Gesundheit, Pflege und Konsumentenschutz. https://info.gesundheitsministerium.at/dashboard.html?l=de. Published 2020.

3. Linton NM, Kobayashi T, Yang Y, et al. Incubation Period and Other Epidemiological Characteristics of 2019 Novel Coronavirus Infections with Right Truncation: A Statistical Analysis of Publicly Available Case Data. J Clin Med. 2020;9(2):538. doi:10.3390/jcm9020538

4. Backer JA, Klinkenberg D, Wallinga J. Incubation period of 2019 novel coronavirus (2019-nCoV) infections among travellers from Wuhan, China, 20-28 January 2020. Eurosurveillance. 2020;25(5). doi:10.2807/15607917.ES.2020.25.5.2000062

5. Dong X, Cao Y, Lu X, et al. Eleven Faces of Coronavirus Disease 2019. Allergy. March 2020. doi:10.1111/all.14289

6. Lin C, Ding Y, Xie B, et al. Asymptomatic novel coronavirus pneumonia patient outside Wuhan: The value of CT images in the course of the disease. Clin Imaging. 2020;63:7-9. doi:10.1016/j.clinimag.2020.02.008

7. Zou L, Ruan F, Huang M, et al. SARS-CoV-2 Viral Load in Upper Respiratory Specimens of Infected Patients. N Engl J Med. 2020;382(12):1177-1179. doi:10.1056/NEJMc2001737

8. Chan JF-W, Yuan S, Kok K-H, et al. A familial cluster of pneumonia associated with the 2019 novel coronavirus indicating person-to-person transmission: a study of a family cluster. Lancet. 2020;395(10223):514-523. doi:10.1016/S0140-6736(20)30154-9

9. Hu Z, Song C, Xu C, et al. Clinical characteristics of 24 asymptomatic infections with COVID-19 screened among close contacts in Nanjing, China. Sci China Life Sci. March 2020. doi:10.1007/s11427-020-1661-4

10. Heymann DL, Shindo N, WHO Scientific and Technical Advisory Group for Infectious Hazards. COVID-19: what is next for public health? Lancet. 2020;395(10224):542-545. doi:10.1016/S0140-6736(20)30374-3

11. Bai Y, Yao L, Wei T, et al. Presumed Asymptomatic Carrier Transmission of COVID-19. JAMA. February 2020. doi:10.1001/jama.2020.2565

12. Mizumoto K, Kagaya K, Zarebski A, Chowell G. Estimating the asymptomatic proportion of coronavirus disease 2019 (COVID-19) cases on board the Diamond Princess cruise ship, Yokohama, Japan, 2020. Euro Surveill. 2020;25(10). doi:10.2807/1560-7917.ES.2020.25.10.2000180 
13. PCR Positives: What Do They Mean?; 2020.

14. Self WH, Tenforde MW, Stubblefield WB, Feldstein LR, Steingrub JS. Seroprevalence of SARS-CoV-2 Among Frontline Health Care Personnel in a Multistate Hospital Network - 13 Academic Medical Centers , April June 2020. MMWR - Morb Mortal Wkly Rep. 2020;69:1-7.

15. Xie X, Zhong Z, Zhao W, Zheng C, Wang F, Liu J. Chest CT for Typical 2019-nCoV Pneumonia: Relationship to Negative RT-PCR Testing. Radiology. February 2020:200343. doi:10.1148/radiol.2020200343

16. Guo L, Ren L, Yang S, et al. Profiling Early Humoral Response to Diagnose Novel Coronavirus Disease (COVID-19). Clin Infect Dis. March 2020. doi:10.1093/cid/ciaa310

17. Kucirka LM, Lauer SA, Laeyendecker O, Boon D, Lessler J. Variation in False-Negative Rate of Reverse Transcriptase Polymerase Chain Reaction-Based SARS-CoV-2 Tests by Time Since Exposure. Ann Intern Med. 2020;173(4):262-267. doi:10.7326/M20-1495

18. Li Y, Yao L, Li J, et al. Stability issues of RT-PCR testing of SARS-CoV-2 for hospitalized patients clinically diagnosed with COVID-19. J Med Virol. 2020;92(7):903-908. doi:10.1002/jmv.25786

19. Li D, Wang D, Dong J, et al. False-negative results of real-time reverse-transcriptase polymerase chain reaction for severe acute respiratory syndrome coronavirus 2: Role of deep-learning-based ct diagnosis and insights from two cases. Korean J Radiol. 2020;21(4):505-508. doi:10.3348/kjr.2020.0146

20. Ferrari D, Sabetta E, Ceriotti $D$, et al. Routine blood analysis greatly reduces the false-negative rate of RT-PCR testing for COVID-19. Acta Biomed. 2020;91(3):1-8. doi:10.23750/abm.v91i3.9843

21. Alter G, Seder R. The Power of Antibody-Based Surveillance. N Engl J Med. 2020:1-2. doi:10.1056/NEJMsa1201918.6.

22. Xiang F, Wang X, He X, et al. Antibody Detection and Dynamic Characteristics in Patients with COVID-19. Clin Infect Dis. April 2020. doi:10.1093/cid/ciaa461

23. Okba N, Muller M, Li W, et al. SARS-CoV-2 specific antibody responses in COVID-19 patients. Emerg Infect Dis. 2020;preprint:1-18. doi:10.1101/2020.03.18.20038059

24. Huang AT, Garcia-Carreras B, Hitchings MDT, et al. A systematic review of antibody mediated immunity to coronaviruses: kinetics, correlates of protection, and association with severity. Nat Commun. 2020;11(1):116. doi:10.1038/s41467-020-18450-4

25. To KK-WW, Tsang OT-YY, Leung W-SS, et al. Temporal profiles of viral load in posterior oropharyngeal saliva samples and serum antibody responses during infection by SARS-CoV-2: an observational cohort study. Lancet Infect Dis. 2020;20(5):565-574. doi:10.1016/S1473-3099(20)30196-1

26. Li Z, Yi Y, Luo X, et al. Development and Clinical Application of A Rapid IgM-IgG Combined Antibody Test for SARS-CoV-2 Infection Diagnosis. J Med Virol. 2020:0-1. doi:10.1002/jmv.25727

27. Lee N-Y, Li C-W, Tsai H-P, et al. A case of COVID-19 and pneumonia returning from Macau in Taiwan: clinical course and anti-SARS-CoV-2 IgG dynamic. J Microbiol Immunol Infect. 2020. doi:10.1016/j.jmii.2020.03.003

28. Corman VM, Landt O, Kaiser M, et al. Detection of 2019 novel coronavirus (2019-nCoV) by real-time RT-PCR. Eurosurveillance. 2020;25(3). doi:10.2807/1560-7917.ES.2020.25.3.2000045

29. Hoffmann M, Kleine-Weber H, Schroeder S, et al. SARS-CoV-2 Cell Entry Depends on ACE2 and TMPRSS2 and Is Blocked by a Clinically Proven Protease Inhibitor. Cell. 2020;181(2):271-280.e8.

doi:10.1016/j.cell.2020.02.052

Page $17 / 23$ 
30. Pollán M, Pérez-Gómez B, Pastor-Barriuso R, et al. Prevalence of SARS-CoV-2 in Spain (ENE-COVID): a nationwide, population-based seroepidemiological study. Lancet. 2020;396(10250):535-544.

doi:10.1016/S0140-6736(20)31483-5

31. Korth J, Wilde B, Dolff S, et al. SARS-CoV-2-specific antibody detection in healthcare workers in Germany with direct contact to COVID-19 patients. J Clin Virol. 2020;128. doi:10.1016/j.jcv.2020.104437

32. European Centre for Disease Prevention and Control - Data on the weekly subnational 14-day notification rate of new COVID-19 cases. https://www.ecdc.europa.eu/en/publications-data/weekly-subnational-14-daynotification-rate-covid-19. Published 2020. Accessed December 11, 2020.

33. Zu ZY, Jiang M Di, Xu PP, et al. Coronavirus Disease 2019 (COVID-19): A Perspective from China. Radiology. February 2020:200490. doi:10.1148/radiol.2020200490

34. Wang D, Hu B, Hu C, et al. Clinical Characteristics of 138 Hospitalized Patients With 2019 Novel CoronavirusInfected Pneumonia in Wuhan, China. JAMA. 2020;323(11):1061. doi:10.1001/jama.2020.1585

35. Xu Z, Shi L, Wang Y, et al. Pathological findings of COVID-19 associated with acute respiratory distress syndrome. Lancet Respir Med. February 2020. doi:10.1016/S2213-2600(20)30076-X

36. Gudbjartsson DF, Norddahl GL, Melsted P, et al. Humoral Immune Response to SARS-CoV-2 in Iceland. N Engl J Med. September 2020:1-11. doi:10.1056/nejmoa2026116

37. Horvath K, Semlitsch T, Jeitler K, Krause R, Siebenhofer A. Antibody tests for COVID-19: What the results tell us. Z Evid Fortbild Qual Gesundhwes. 2020. doi:10.1016/j.zefq.2020.05.005

38. BMSGPK. COVID-19-Impfungen: Anwendungsempfehlungen Des Nationalen Impfgremiums.; 2021. https://www.sozialministerium.at/dam/jcr:c8dcc8fe-4ec3-4eb7-b1fb-86cc75845f93/COVID-19Impfungen_Anwendungsempfehlung_des_Nationalen_Impfgremiums_Version_1.2_(Stand_25.01.2021).pdf.

39. Robert Koch Institut. Epidemiologisches Bulletin - Beschluss der STIKO zur 1. Aktualisierung der COVID-19Impfempfehlung. 2021:1-74. https://www.sozialministerium.at/dam/jcr:c8dcc8fe-4ec3-4eb7-b1fb86cc75845f93/COVID-19-

Impfungen_Anwendungsempfehlung_des_Nationalen_Impfgremiums_Version_1.2_(Stand_25.01.2021).pdf.

40. CDC. Frequently Asked Questions about COVID-19 Vaccination. https://www.cdc.gov/coronavirus/2019ncov/vaccines/faq.html. Published 2021. Accessed January 29, 2021.

\section{Tables}

Table 1 Sociodemographic Variables - All Groups 


\begin{tabular}{|c|c|c|c|c|}
\hline $\begin{array}{l}\text { Sociodemographic } \\
\text { variables }\end{array}$ & $\begin{array}{l}\text { Total group } \\
(n=3301)\end{array}$ & $\begin{array}{l}\text { Positive } \\
\text { during study } \\
(n=32)\end{array}$ & $\begin{array}{l}\text { Prior positive PCR } \\
\text { - Group } A(n=15)\end{array}$ & $\begin{array}{l}\text { Positive LFA and/or } \\
\text { ELISA - Group B ( } n=17)\end{array}$ \\
\hline $\operatorname{Sex}(f / m)$ & $\begin{array}{l}2246 \\
(68 \%) / 1049 \\
(31.8 \%)^{*}\end{array}$ & $\begin{array}{l}21(65.6 \%) / 11 \\
(34.4 \%)\end{array}$ & $\begin{array}{l}9(60.0 \%) / 6 \\
(40.0 \%)\end{array}$ & $12(70.6 \%) / 5(29.4 \%)$ \\
\hline \multirow[t]{2}{*}{ Age } & $43.6 \pm 10.5$ & $40.5 \pm 9.7$ & $39.4 \pm 9.4$ & $41.5 \pm 10.1$ \\
\hline & $\begin{array}{l}(\operatorname{Min}=16, \\
\operatorname{Max}=66)\end{array}$ & $\begin{array}{l}(\operatorname{Min}=28, \\
\operatorname{Max}=55)\end{array}$ & $(\operatorname{Min}=28, \operatorname{Max}=55)$ & $(\operatorname{Min}=28, \operatorname{Max}=54)$ \\
\hline \multicolumn{5}{|l|}{ Function } \\
\hline Nurses & $1318(39.9 \%)$ & $13(40.6 \%)$ & $6(40.0 \%)$ & $7(41.2 \%)$ \\
\hline Medical doctors & 397 (12.0\%) & $7(21.9 \%)^{\star \star}$ & $3(20.0 \%)$ & $4(23.5 \%)$ \\
\hline $\begin{array}{l}\text { Physiotherapists or } \\
\text { occupational } \\
\text { therapists }\end{array}$ & $270(8.2 \%)$ & $2(6.3 \%)$ & $1(6.7 \%)$ & $1(5.9 \%)$ \\
\hline $\begin{array}{l}\text { Speech and language } \\
\text { therapists }\end{array}$ & $8(0.2 \%)$ & $0(0 \%)$ & $0(0 \%)$ & $0(0 \%)$ \\
\hline Radiographers & $156(4.7 \%)$ & $1(3.1 \%)$ & $1(6.7 \%)$ & $0(0 \%)$ \\
\hline Laboratory staff & $33(1 \%)$ & $0(0 \%)$ & $0(0 \%)$ & $0(0 \%)$ \\
\hline Dietologists & $12(0.4 \%)$ & $0(0 \%)$ & $0(0 \%)$ & $0(0 \%)$ \\
\hline Cleaning staff & $150(4.5 \%)$ & $1(3.1 \%)$ & $1(6.7 \%)$ & $0(0 \%)$ \\
\hline Typists & $156(4.7 \%)$ & $0(0 \%)$ & $0(0 \%)$ & $0(0 \%)$ \\
\hline Janitorial service & $101(3.1 \%)$ & $1(3.1 \%)$ & $0(0 \%)$ & $0(0 \%)$ \\
\hline Reception & $40(1.2 \%)$ & $0(0 \%)$ & $0(0 \%)$ & $0(0 \%)$ \\
\hline Administrative Staff & $311(9.4 \%)$ & $2(6.3 \%)$ & $1(6.7 \%)$ & $1(5.9 \%)$ \\
\hline Other & 305 (9.2\%) & $4(12.5 \%)$ & $2(13.3 \%)$ & $2(11.8 \%)$ \\
\hline \multirow{2}{*}{$\begin{array}{l}\text { No. of persons per } \\
\text { household/ }\end{array}$} & $2.72 \pm 1.3 /$ & $2.34 \pm 1.5 /$ & $2.40 \pm 1.4 /$ & $2.29 \pm 1.6$ \\
\hline & $1064(32.2 \%)$ & $8(25.0 \%)$ & $4(26.7 \%)$ & $4(23.5 \%)$ \\
\hline
\end{tabular}

*...6 $(0.2 \%)$ refused to disclose their gender; ${ }^{* *}$...overrepresented compared to total group

Table 2 Health Variables - All Groups 


\begin{tabular}{|lllll|}
\hline Health Variables & $\begin{array}{l}\text { Total } \\
\text { group } \\
(\mathbf{n = 3 3 0 1 )}\end{array}$ & $\begin{array}{l}\text { Positive during } \\
\text { study (n=32) }\end{array}$ & $\begin{array}{l}\text { Prior positive PCR - } \\
\text { Group A (n=15) }\end{array}$ & $\begin{array}{l}\text { Positive LFA and/or ELISA } \\
- \text { Group B (n=17) }\end{array}$ \\
\hline Hypertension & $\begin{array}{l}257 \\
(7.8 \%)\end{array}$ & $3(9.4 \%)$ & $1(6.7 \%)$ & $2(11.8 \%)$ \\
\hline Diabetes Mellitus & $\begin{array}{l}41 \\
(1.2 \%)\end{array}$ & $0(0 \%)$ & $0(0 \%)$ & $0(0 \%)$ \\
\hline $\begin{array}{l}\text { Coronary Artery } \\
\text { Disease }\end{array}$ & $\begin{array}{l}19 \\
(0.6 \%)\end{array}$ & $1(3.1 \%)$ & $1(6.7 \%)$ & $0(0 \%)$ \\
\hline CoPD & $\begin{array}{l}43 \\
(1.3 \%)\end{array}$ & $0(0 \%)$ & $0(0 \%)$ & $0(0 \%)$ \\
\hline $\begin{array}{l}\text { Chronic Kidney } \\
\text { Disease }\end{array}$ & $\begin{array}{l}14 \\
(0.4 \%)\end{array}$ & $0(0 \%)$ & $0(0 \%)$ & $1(5.9 \%)$ \\
\hline Immunocompromised & $\begin{array}{l}31 \\
(0.9 \%)\end{array}$ & $1(3.1 \%)$ & $0(0 \%)$ & $6(35.3 \%)$ \\
\hline Allergies & $\begin{array}{l}1116 \\
(33.8 \%)\end{array}$ & $14(43.8 \%)$ & $8(53.3 \%)$ & $2(11.8 \%)$ \\
\hline Smoker & $\begin{array}{l}769 \\
(23.3 \%)\end{array}$ & $5(15.6 \%)$ & $3(20.0 \%)$ & \\
\hline
\end{tabular}

Table 3: Symptoms - All Groups

\begin{tabular}{|llll|}
\hline Symptoms & $\begin{array}{l}\text { Positive during } \\
\text { study }(\mathbf{n}=32)\end{array}$ & $\begin{array}{l}\text { Prior positive PCR - } \\
\text { Group A }(\mathbf{n}=15)\end{array}$ & $\begin{array}{l}\text { Positive LFA and/or ELISA - } \\
\text { Group B (n=17) }\end{array}$ \\
\hline $\begin{array}{l}\text { At least one } \\
\text { symptom }\end{array}$ & 13 & 8 & 5 \\
\hline Fever & $3(9.4 \%)$ & $2(13.3 \%)$ & $1(5.9 \%)$ \\
\hline Cough & $4(12.5)$ & $3(20.0 \%)$ & $1(5.9 \%)$ \\
\hline Dyspnea & $0(0 \%)$ & $0(0 \%)$ & $0(0 \%)$ \\
\hline Rhinitis & $7(21.9 \%)$ & $4(26.7 \%)$ & $3(17.6 \%)$ \\
\hline Sore throath & $5(15.6 \%)$ & $4(26.7 \%)$ & $1(5.9 \%)$ \\
\hline Headache & $6(18.8 \%)$ & $3(20.0 \%($ & $3(17.6 \%)$ \\
\hline Melalgia & $5(15.6 \%)$ & $3(20.0 \%)$ & $2(11.8 \%)$ \\
\hline $\begin{array}{l}\text { Loss of taste and } \\
\text { olfaction }\end{array}$ & $7(21.9 \%)$ & $6(40.0 \%)$ & $1(5.9 \%)$ \\
\hline Diarrhea & $3(9.4 \%)$ & $2(13.3 \%)$ & $1(5.9 \%)$ \\
\hline
\end{tabular}


Figures

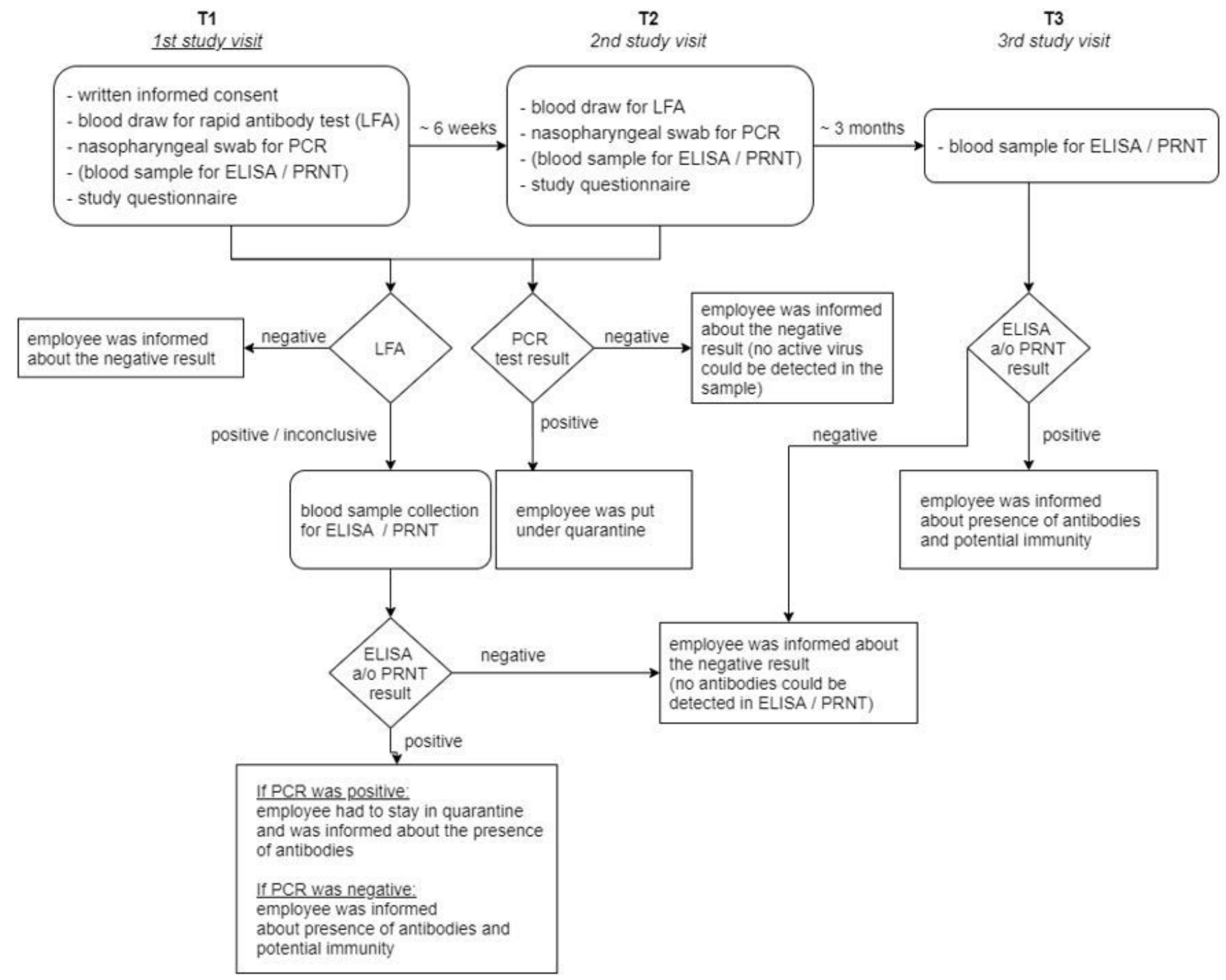

Figure created with draw.io

Figure 1

Study procedures 


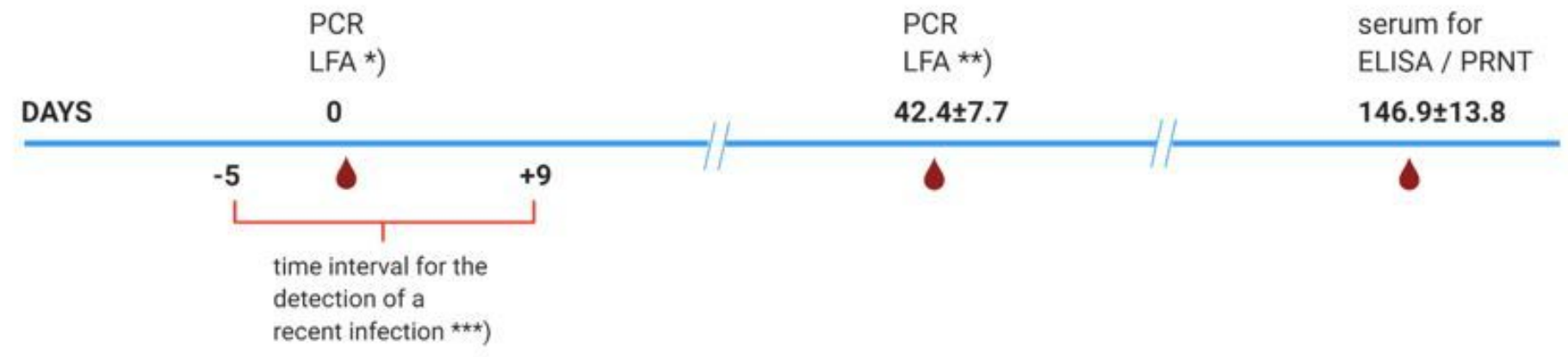

*) in case of a positive or inconclusive result in the rapid antibody test (LFA): blood sample collection for laboratory-based ELISA and PRNT

$\left.{ }^{\star *}\right)$ in case of a positive or inconclusive result in the rapid antibody test (LFA) at T2 and/or T2: blood sample collection for laboratory-based ELISA and PRNT

***) New infections, together with the reported number of infections which are inquired by the Austrian government, should 1) inform conclusions whether there is a specific risk for health care workers ( $\mathrm{HCW})$, and 2) detect recent asymptomatic infections thereby enabling the calculation of the actual rate of infections.

\section{Figure created with Biorender.com}

\section{Figure 2}

time intervals of testing
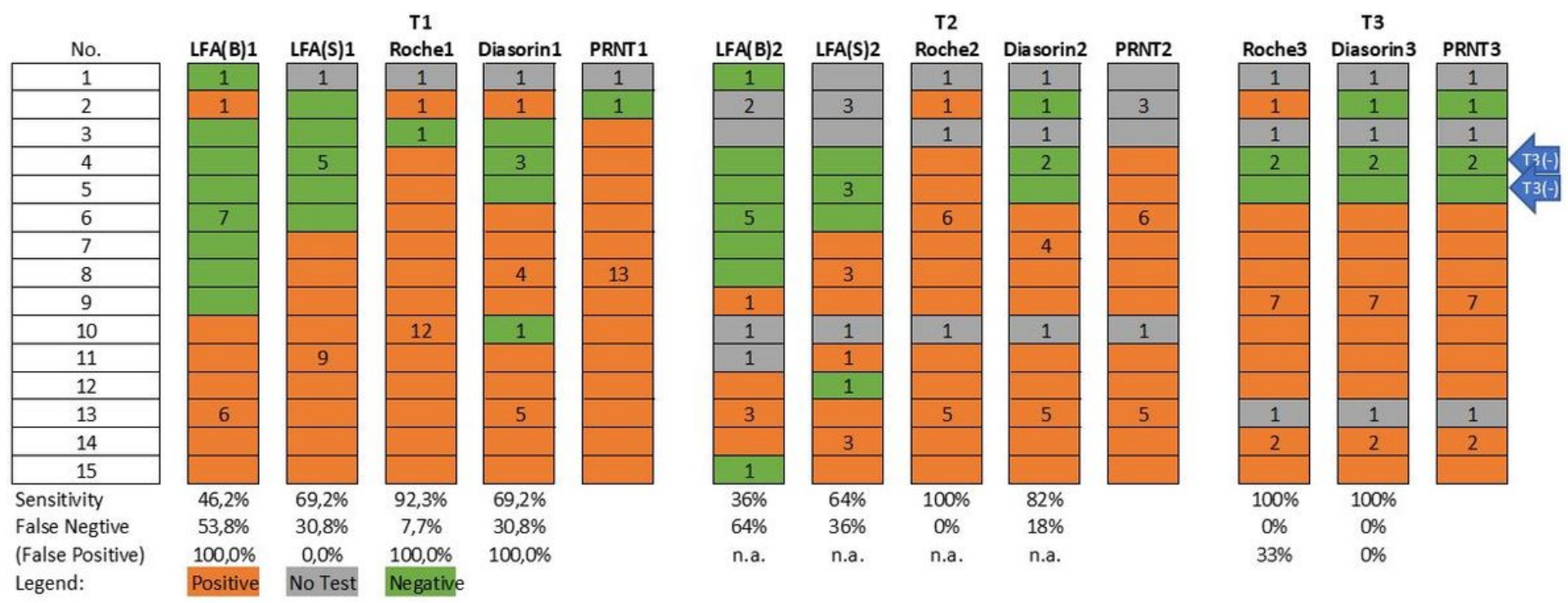

\section{Figure 3}

Group A - PRNT, ELISA (Roche and Diasorin) and rapid antibody test (LFA) with either whole blood (LFA(B)) or blood serum (LFA(S)) at T1, T2 and T3 


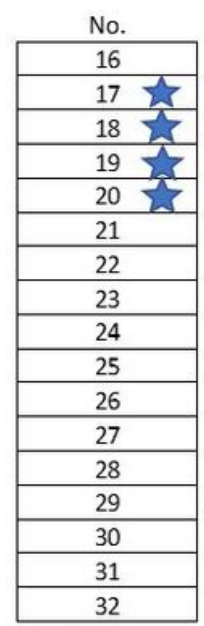

Sensitivity False Negtive

(False Positive) Legend:
T1

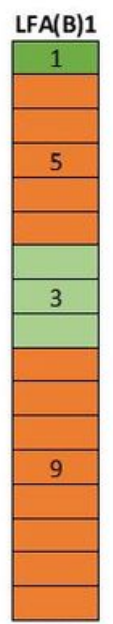

$83,3 \%$ $25,0 \%$

$100 \%$ Positive
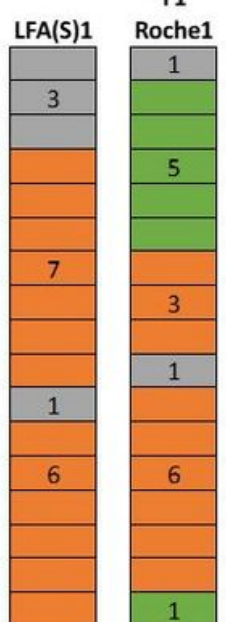

$100 \%$

$0 \% \quad 18,2 \%$

$0 \% \quad 0 \%$
Diasorin1

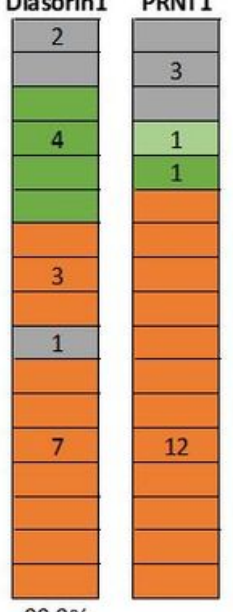

$90,9 \%$

$9,1 \%$

$0 \%$
T2

LFA(B) $2 \quad$ LFA(S) 2

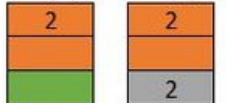

Roche2

Diasorin2

\begin{tabular}{|l|}
\hline 1 \\
\hline 1 \\
\hline 2 \\
\hline
\end{tabular}

\begin{tabular}{|l|}
\hline 2 \\
\hline 2 \\
\hline
\end{tabular}

\begin{tabular}{|l|}
\hline \\
\hline \\
\hline
\end{tabular}

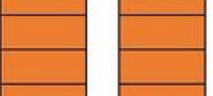

\begin{tabular}{|l|l|}
\hline & \\
\hline & \\
\hline 10 & \\
\hline 11 \\
\hline
\end{tabular}

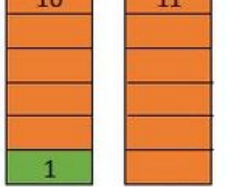

$92 \% \quad 100 \%$

$8 \% \quad 0 \%$

$0 \% \quad 0 \%$
T3

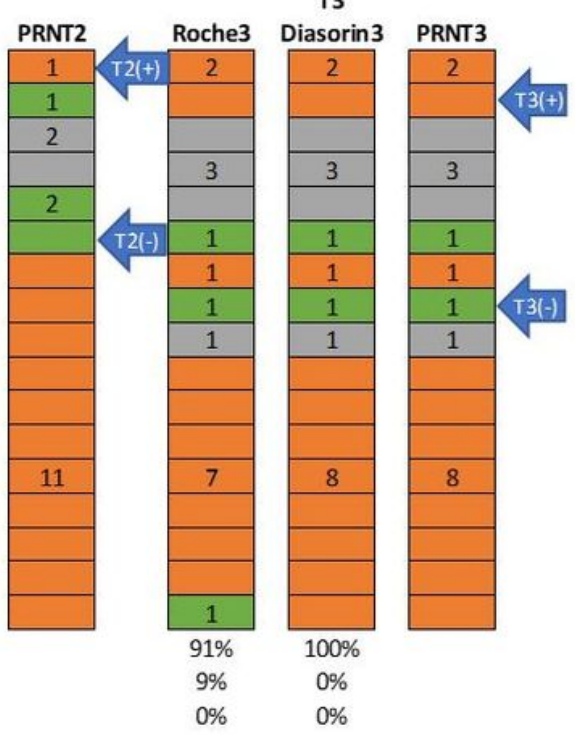

Figure 4

Group B - PRNT, ELISA (Roche and Diasorin) and rapid antibody test (LFA) with either whole blood (LFA(B)) or serum (LFA(S)) at T1, T2 and T3 